WellBeing International

WBI Studies Repository

$12-2017$

\title{
Does the Stress Inherent to Laboratory Life and Experimentation on Animals Adversely Affect Research Data?
}

Jarrod Bailey

Cruelty Free International

Follow this and additional works at: https://www.wellbeingintlstudiesrepository.org/valaexp

Part of the Animal Experimentation and Research Commons, Animal Studies Commons, and the Design of Experiments and Sample Surveys Commons

\section{Recommended Citation}

Bailey, J. (2017). Does the stress inherent to laboratory life and experimentation on animals adversely affect research data?. Alternatives to laboratory animals: ATLA, 45(6), 299.

This material is brought to you for free and open access by WellBeing International. It has been accepted for inclusion by an authorized administrator of the WBI Studies Repository. For more information, please contact wbisr-info@wellbeingintl.org.

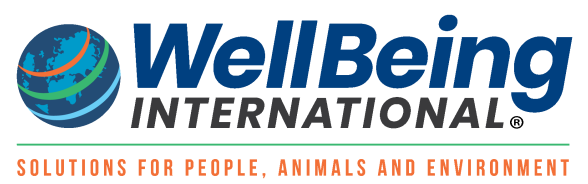




\title{
Does the Stress Inherent to Laboratory Life and Experimentation on Animals Adversely Affect Research Data?
}

\author{
Jarrod Bailey
}

\begin{abstract}
Stress and distress in laboratory animals is often inherent and unavoidable.
The effect of these factors on the reliability and relevance of experimental data is not sufficiently appreciated. Greater awareness, debate and discussion of this issue are urgently required
\end{abstract}

Stress and distress - widely acknowledged to be difficult to accurately define and distinguish — are phenomena common to many species in the form of "physical, mental, or emotional strain or tension", or "a condition or feeling experienced when a person [or non-human animal] perceives that demands exceed the personal and social resources the individual is able to mobilize." 1 As the American Institute of Stress says (and it should know), "...all of our experimental and clinical research confirms that the sense of having little or no control is always distressful - and that's what stress is all about." 1

It cannot seriously be denied that "having little or no control" is an aspect of life for animals in laboratories; and so, it therefore follows, are stress and distress. Indeed, stress and distress have been documented and investigated in many diverse species, and can lead to depression, anxiety, and altered and sometimes harmful physiological responses. ${ }^{2}$ Members of the animal welfare and protection communities have, understandably and correctly, questioned whether enough is being done to understand the concept of stress and distress, to mitigate their effects and consequences by improving the welfare of the animals involved, and to account for any remaining effects in the interpretation of experimental data and results. Are data from stressed and distressed animals in laboratories comparable and relevant to less stressed members of the same species, such as those living in the wild? What about the relevance of the data to the 'typical' human being, who is supposed to benefit from research that utilises stressed and distressed animals?

There is compelling evidence that life in a laboratory for an animal, perhaps particularly one which undergoes invasive procedures, is inherently and unavoidably stressful. ${ }^{3}$ Not only is there "little or no control" or agency, but also many natural behaviours are precluded, such as foraging, hiding, nesting/building, escaping, and exploring. In addition, the animals are subjected to procedures, interventions and environments that they would normally avoid, such as transportation, restraint, gavage, blood draws, even simple handling and weighing, general poor housing conditions, anaesthesia, and, for them, unusual food and water availability. They also experience other negative environmental factors, such as artificial noise, odours, temperature and light levels, sudden changes in noise level, social crowing and/or isolation, cage changing or cleaning, observation of procedures on, or killing of, other animals.

All of this naturally has serious welfare implications. Much like excessive psychological stress in humans may lead to an array of altered/longerterm adverse behavioural states such as PTSD, anxiety and depression, this is also evidenced in non-human species, often in the form of stereotypies. These are abnormal behaviours manifesting as repetitive, invariant behaviour patterns with no obvious goal or function, or even self-harm. ${ }^{4}$

Efforts that are made to mitigate stressors and their consequences are, of course, necessary and welcome. Whether this is acceptably successful and sufficient from a welfare perspective, however, is debatable, but this is not the main issue of this Editorial. There are also scientific implications. While these confounding issues are acknowledged in some quarters - for instance, handling stress is accepted as a source of "unexplained variation within and between animal studies", as it influences "both the behaviour and physiology of animals",5,6 and relatively poor caging conditions "may contribute to problems in translating murine research into human studies"7 - it is also accepted by some that they are widely under-appreciated, and, it could be argued, under-researched. If this is the case, then the harm-benefit balance on which animal experiments are predicated is tipped against their validity from both sides. As a result, the harm to the animals 
involved is greater than acknowledged, and the benefits to humans can only be less than speculated.

While direct evidence showing the confounding effects of stress/distress on experimental data may be relatively scant, it should not be inferred (as it is by some) that they do not exist, or that they are not an important issue. There are plentiful data on the biological mechanisms of stress, showing how direct physiological sequelae must, undeniably, exert comprehensive and wide-ranging confounding effects. Briefly: neuroendocrine changes are elicited via multiple fundamental biological networks; elevated serum 'stress hormones' (cortisol/corticosterone, or 'CORT'), heart rate, blood pressure and other hormones are associated with stereotypies; these in turn are linked with adverse physiological effects, including increased risk of disease and onset and exacerbation of a range of somatic disorders. This seems obvious when one considers that human symptoms of stress include anger, depression, anxiety, behavioural changes, food cravings, lack of appetite, frequent crying, difficulty sleeping, tiredness, lack of concentration, chest pains, constipation, diarrhoea, cramps and muscle spasms, dizziness, fainting, nervous twitches, restlessness, sexual dysfunctions, breathlessness, and a host of diseases and illnesses believed to have an associated psychogenic (as well as physiological) cause that either actually leads to the disease, accelerates the disease process, or intensifies it symptoms.

The biological mechanisms associated with the above are powerful, and include changes in gene regulation and expression, with consequences for immune function, central nervous system pathology, cardiovascular perturbations, and more. Effects in animals include: altered brain development, structure, function and physiology; psychopathologies and mental illnesses; cardiovascular diseases; autoimmune disorders; general disease susceptibility; various cancers; GI disorders; multiple sclerosis; inflammatory bowel disease; type 2 diabetes; osteoporosis; and arthritis.

Some may argue that such effects are mitigated via habituation and/or desensitisation of the animals subjected to laboratory and research stressors. While there is evidence that this might be the case to some degree and in some circumstances, there is also substantial evidence to the contrary - i.e. that stress may become worse due to repeat exposures; that habituation/desensitisation applies to only some types of stressor and not others; that while some indicators of stress may decrease, others do not, confounding the issue; and so on (see various examples ${ }^{7-13)}$.

Other confounding factors may include prenatal and/or early-life stress, as experienced by animals conceived, born and reared in breeding centres and laboratories. These animals will be subjected to disturbed neuroendocrine function leading to, for example, altered/compromised brain development and behavioural abnormalities, modulated and/or compromised immune function. ${ }^{14}$ Transgenerational effects of maternal stress are also an issue - it appears that the offspring (not limited to the first generation) of stressed animals, such as wild-caught monkeys, animals in breeding facilities, or those that have undergone transportation or other similarly stressful events, inherit stress-associated epigenetic modifications that alter gene expression and function, affecting, for example, growth, metabolism, cancer susceptibility, immune function, and stress responses. 15

It is appreciated, of course, that stress is not limited to animals in laboratories. It is a natural and frequently important facet of life for many species, which serves a crucial purpose. My point here - supported by many peer-reviewed studies - is that, for animals in laboratories, stress is frequent, significant, unavoidable, a result of unnatural events that would not be encountered in the animals' natural habitat, and is therefore far from benign. As such, it has adverse consequences for animal welfare, and (more to the point of this article) for many facets of data relevance and reliability, due to effects on a wide range of physiological systems. Professional bodies, such as the US National Research Council, agree. Indeed, they have gone further, opining that even relatively mild stress in laboratory animals can affect their responses to toxic chemicals, their performance in behavioural tests, their immune function, and morbidity and mortality, among other things. ${ }^{16}$

This is not something that can be overcome through the use of more animals, and by designing experiments more carefully and with greater refinements. While acknowledging efforts on this issue over many years, I argue that, due to fundamental biology and interspecies biological differences, 17,18 attending to and improving husbandry, veterinary care, regulation, oversight, training and the like, is not - and never can be - enough to significantly address and overcome the associated problems. I would therefore urge scientists who use animals in invasive laboratory experiments, and bodies that fund, commission and oversee such research, to engage with and address these issues more overtly and vigorously, and to enter debate and discussion for the benefit of all concerned - human and nonhuman. To promote this crucial discussion, an ATLA Special Issue on this topic is planned for 2018. It is hoped that parties from both viewpoints will be encouraged to join the debate by submitting articles on this issue, in response to this Editorial.

\section{Dr Jarrod Bailey}

Senior Research Scientist

Cruelty Free International

London

$U K$

E-mail: jarrod.bailey@crueltyfreeinternational.org 


\section{References}

1 The American Institute of Stress (2017). What is stress? Available at: http://www.stress.org/what-isstress/ (Accessed 13.09.17).

2 Maestripieri, D. \& Hoffman, C.L. (2011). Chronic stress, allostatic load, and aging in nonhuman primates. Development \& Psychopathology 23, 11871195.

3 Balcombe, J.P. (2006). Laboratory environments and rodents' behavioural needs: A review. Laboratory Animals 40, 217-235.

4 Prescott, M.J., Morton, D.B., Anderson, D., Buckwell, A., Heath, M.S., Hubrecht, R., Jennings, M., Robb, M.D., Ruane, M.B. \& Swallow, M.J. (2004). Refining dog husbandry and care. Laboratory Animals 38, 194.

5 Gouveia, K. \& Hurst, J.L. (2013). Reducing mouse anxiety during handling: Effect of experience with handling tunnels. PLoS One 8, e66401.

6 Balcombe, J.P., Barnard, N.D. \& Sandusky, C. (2004). Laboratory routines cause animal stress. Contemporary Topics in Laboratory Animal Science 43, 42-51.

7 Gurfein, B.T., Stamm, A.W., Bacchetti, P., Dallman, M.F., Nadkarni, N.A., Milush, J.M., Touma, C., Palme, R., Di Borgo, C.P., Fromentin, G., Lown-Hecht, R., Konsman, J.P., Acree, M., Premenko-Lanier, M., Darcel, N., Hecht, F.M. \& Nixon, D.F. (2012). The calm mouse: An animal model of stress reduction. Molecular Medicine 18, 606-617.

8 Meller, A., Kasanen, I., Ruksenas, O., Apanaviciene, N., Baturaite, Z., Voipio, H.M. \& Nevalainen, T. (2011). Refining cage change routines: Comparison of cardiovascular responses to three different ways of cage change in rats. Laboratory Animals 45, 167-173.

9 Swan, M.P. \& Hickman, D.L. (2014). Evaluation of the neutrophil-lymphocyte ratio as a measure of distress in rats. Lab Animal 43, 276-282.

10 Barnum, C.J., Blandino, P.J. \& Deak, T. (2007). Adaptation in the corticosterone and hyperthermic responses to stress following repeated stressor exposure. Journal of Neuroendocrinology 19, 632-642.
11 Longordo, F., Fan, J., Steimer, T., Kopp, C. \& Luthi, A. (2011). Do mice habituate to "gentle handling?" A comparison of resting behavior, corticosterone levels and synaptic function in handled and undisturbed C57BL/6J mice. Sleep 34, 679-681.

12 Kramer, K., van de Weerd, H., Mulder, A., Van Heijningen, C., Baumans, V., Remie, R., Voss, H.P. \& van Zutphen, B.F. (2004). Effect of conditioning on the increase of heart rate and body temperature provoked by handling in the mouse. ATLA 32, Suppl. 1A, 177181.

13 Clement, J.G., Mills, P. \& Brockway, B. (1989). Use of telemetry to record body temperature and activity in mice. Journal of Pharmacological Methods 21, 129 140.

14 Butkevich, I., Mikhailenko, V., Semionov, P., Bagaeva, T., Otellin, V. \& Aloisi, A.M. (2009). Effects of maternal corticosterone and stress on behavioral and hormonal indices of formalin pain in male and female offspring of different ages. Hormones \& Behavior 55, 149-157.

15 Zambrano, E., Martinez-Samayoa, P.M., Bautista, C.J., Deas, M., Guillen, L., Rodriguez-Gonzalez, G.L., Guzman, C., Larrea, F. \& Nathanielsz, P.W. (2005). Sex differences in transgenerational alterations of growth and metabolism in progeny (F2) of female offspring (F1) of rats fed a low protein diet during pregnancy and lactation. Journal of Physiology $\mathbf{5 6 6}$, $225-236$.

16 National Research Council (US) Committee on Recognition and Alleviation of Distress in Laboratory Animals (2008). Recognition and Alleviation of Pain and Distress in Laboratory Animals, 198pp. Washington, DC, USA: National Academies Press. Available at: https://www.ncbi.nlm.nih.gov/books/ NBK4032/ (Accessed 13.09.17).

17 Bailey, J. (2011). Lessons from chimpanzee-based research on human disease: The implications of genetic differences. ATLA 39, 527-540.

18 Bailey, J. (2014). Monkey-based research on human disease: The implications of genetic differences. ATLA 42, 287-317. 